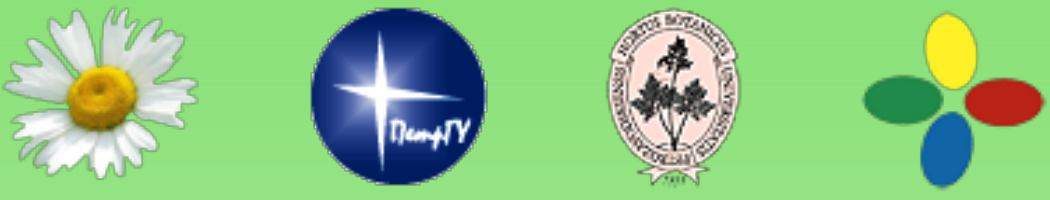

\section{HORTUS BOTANICUS}

Международный электронный журнал ботанических садов

\section{$11 / 2016$}

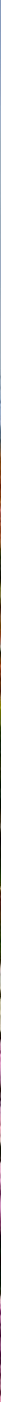


Информационно-аналитический центр Совета ботанических садов России при Ботаническом саде Петрозаводского государственного университета

\section{HORTUS BOTANICUS}

Международный электронный журнал ботанических садов

\section{$11 / 2016$}

ISSN 1994-3849

Эл № ФС 77-33059 от 11.09.2008

Главный редактор
А. А. Прохоров

Редакционный совет

Редакционная коллегия

Редакция

П. Вайс Джексон

Г. С. Антипина

К. А. Васильева

А. С. Демидов

Е. М. Арнаутова

А. В. Еглачева

T. С. Маммадов

А. В. Бобров

С. М. Кузьменкова

В. Н. Решетников

Ю. К. Виноградова

А. Г. Марахтанов

Т. М. Черевченко

Е. В. Голосова

Ю. Н. Карпун

В. Я. Кузеванов

Е. Ф. Марковская

Ю. В. Наумцев

Е. В. Спиридович

А. И. Шмаков

\section{Адрес редакции}

185910, Республика Карелия, г. Петрозаводск, ул. Красноармейская, 31, каб. 12.

E-mail: hortbot@gmail.com

http://hb.karelia.ru

(c) 2001 - 2016 A. A. Прохоров

\section{На обложке:}

На Балу хризантем в Никитском ботаническом саду (фото Ю. Югансона)

\section{Разработка и техническая поддержка}

Отдел объединенной редакции научных журналов ПетрГУ, РЦ НИТ ПетрГу, Ботанический сад ПетрГу 


\section{Гипотезы, открытия и технологии}

\section{Возможные механизмы охлаждения поверхности растений}

\section{ПРОХОРОВ Алексей Анатольевич}

\section{Ключевые слова:}

гипотеза, точка росы, температура растений, конденсация росы, светоотражение, транспирация, парадокс Мпембы, тепловое излучение, биоэлектричество

Получена: 08 декабря 2016 года

\author{
Петрозаводский государственный университет, \\ alpro@onego.ru
}

\section{Аннотация:}

Кратко рассмотрены основные возможные механизмы охлаждения поверхности растений, приводящие $\mathrm{K}$ конденсации атмосферной влаги. Предлагаются методы экспериментальной проверки данных механизмов.

Подписана к печати: 24 декабря 2016 года

Обычно растения достаточно неподвижны и для того, чтобы обеспечивать себя водой они могут либо отрастить корни подлиннее, либо приспособиться дожидаться дождя или тумана. Но даже при отсутствии дождя или тумана, в атмосфере Земли всегда есть вода (Beysens, 1995), просто надо уметь ее готовить.

Это возможно, если доступная для воздуха поверхность растения имеет температуру $\left(T_{L}\right)$ ниже точки росы $\left(T_{D}\right)$.

В 2013 году мною была предложена гипотеза (Прохоров, 2013), состоящая в том, что растения активно конденсируют атмосферную влагу на своей поверхности за счет снижения температуры поверхности побегов и листьев ниже точки росы, при температуре воздуха $\mathrm{T}_{\mathrm{A}}>\mathrm{T}_{\mathrm{D}}$, T.е. при отсутствии тумана. При этом под словом «активно» понимается как снижение температуры поверхности за счет физиологических и физических механизмов, так и увеличение объема конденсируемой воды за счет увеличения поверхности кроны.

Наблюдения в оранжереях Ботанического сада Петра Великого БИН имени В. Л. Комарова РАН (БС, Санкт-Петербург) и на коллекциях открытого грунта Субтропического ботанического сада Кубани (СБСК, Сочи) подтвердили данное предположение (Прохоров, 2015а; Карпун и др., 2015) и позволили определить оптимальные условия конденсации атмосферной влаги. При условии $\Delta \mathrm{T}_{\mathrm{AD}}=\mathrm{T}_{\mathrm{A}}-\mathrm{T}_{\mathrm{D}} \leq 19,5^{\circ}$ С всегда можно найти растение, способное конденсировать атмосферную влагу на своей поверхности. При $\Delta \mathrm{T}_{\mathrm{AD}} \leq 10^{\circ} \mathrm{C}$, значительная часть растений способна к самоорошению.

Сопоставление отклонения значений среднемесячных температур от точки росы в различных регионах мира (Прохоров, 2015b) позволяет считать это явление повсеместно распространенным, за исключением континентальных аридных территорий с низкой относительной влажностью воздуха. Практически во всем диапазоне климатических условий Земли, при положительных температурах воздуха и почвы, т.е. в период вегетации, растения всегда обладают возможностью извлечь атмосферную влагу и перевести ее в жидкое состояние, доступное для употребления. Эта способность имеет особое значение для обитателей аридных территорий. Сведения о наиболее эффективных конденсаторах росы растительного и животного мира Земли представлены в недавнем обзоре (Malik и др., 2014).

Дальнейшее изучение явления требует рассмотрения возможных механизмов охлаждения поверхности листьев и побегов.

**

Для растений существует две основных стратегии охлаждения поверхности, которые могут быть 
использованы одновременно или порознь - не нагреваться и быстро остывать.

\section{Отражение тепла}

Растения, обитающие в аридных регионах или при высоком уровне инсоляции (высокогорья, морские побережья), обладают светоотражающей поверхностью, защищающей их от перегрева и созданной либо с использованием покрытия из растительных восков и пигментов, либо из разнообразных структур: игл, волосков, чешуй (Gausman, 1969).

Для изучения вклада данного эффекта достаточно сопоставить температуру поверхности сортов одного вида растений с различной пигментацией или опушенностью листьев. Целесообразно исследовать спектры отражения поверхности листьев в ближнем инфракрасном диапазоне.

\section{Пассивное испарительное охлаждение}

Влажная почва может остывать за счет испарительного охлаждения, но высшие растения практически лишены такой возможности, т.к. обладают различными приспособлениями, ограничивающими пассивное испарение воды. С другой стороны, растения могут охлаждаться за счет испарения синтезируемых хладоагентов с более низкой температурой кипения, т.е. более эффективных чем вода - эфирных масел, что также препятствует перегреву растений на открытых освещенных пространствах.

Явление может быть изучено путем сопоставления температуры поверхности культиваров ароматических растений, различающихся по содержанию ароматических веществ.

\section{Активное охлаждение}

Предполагается, что растения располагают механизмами транспирационного охлаждения (Curtis, 1936; Gates, 1968). Известно, что температура транспирирующего листа растений по сравнению с температурой нетранспирирующих листьев (смазанных вазелином или отрезанных) оказывается существенно (до $15,7^{\circ} \mathrm{C}$ ) ниже (Lange, Lange, 1963) .

Сомнение в транспирационной природе снижения температуры у растений вызывает тот факт, что эпифитное растение Tillandsia usneoides L. (испанский мох), у которого нет корневой системы (в обычном понимании), обладает аналогичной способностью постоянно поддерживать низкую температуру при отсутствии прямого солнечного освещения. Это растение не только ограничено водными ресурсами, но и обладает САМ-типом фотосинтеза, и понижение $\mathrm{T}_{\mathrm{L}}$ в дневное время не может быть вызвано транспирацией. В этой связи любопытен тот факт, что до распространения кондиционеров испанский мох применялся для набивки особо прохладных матрасов (Tillandsia usneoides, 2015). Аналогично, низкая дневная температура стеблевых суккулентов, наблюдавшаяся нами в отсутствии интенсивной инсоляции в оранжерее БИН РАН, не может быть объяснена испарением влаги с их поверхности.

По нашим данным (Прохоров, 2015а), значительное число видов растений с обычными типами фотосинтеза в ночной период при отсутствии транспирации, продолжают сохранять $T_{L} \leq T_{D} A$. Tаким образом, вопрос о роли транспирации в охлаждении поверхности растений остается открытым.

\section{Увеличение интенсивности теплового излучения}

Пожалуй, наиболее изысканным приспособлением является аккумулирование тепла в массивных плодах или в стеблях кактусов, которые, как известно (Лархер, 1978), интенсивно нагреваются на солнце. Тогда, после захода солнца вступает в силу парадокс Мпембы (Mpemba, Osborne, 1969), который гласит, что при определенных условиях горячая вода может замёрзнуть быстрее чем холодная, хотя при этом она должна пройти температуру холодной воды в процессе замерзания. Таким образом, арбузы и кактусы могут остыть до точки росы достаточно быстро и, тем самым, увеличить продолжительность конденсации атмосферной влаги.

\section{Биоэлектричество}

В обзоре исследований конденсации росы живыми организмами показано, что капли воды часто 
формируются на иглах и на иных конических структурах (Malik et al., 2014). При этом кончик игл кактусов обладает наибольшим коэффициентом теплового излучения и более высокой температурой (Malik et al. 2015a) по сравнению с основанием иглы. Эти наблюдения заставляют вспомнить эффект Кирлиан (Кирлиан, Кирлиан, 1964), демонстрирующий повышенную интенсивность разрядов на аналогичных конических участках листьев растений. Тогда понижение температуры растений, о чем свидетельствуют капли росы на иглах кактусов, не связано с транспирацией, т.к. кактусу это вредно. Скорее мы наблюдаем некий биоэлектрический феномен, сопряженный с активацией диссоциации молекул воды, своего рода постоянную иглотерапию. Косвенно это подтверждается прекращением выпадения росы при удалении игл у Mammillaria columbiana subsp. yucatanensis (Malik et al., 2015b).

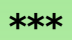

Вышеперечисленные механизмы охлаждения растений могут рассматриваться как адаптации, направленные на достижение точки росы на поверхности растений в условиях недостатка влаги. Разумеется, это не полный перечень возможных механизмов, но достаточный для постановки первых экспериментов, направленных на доказательство роли точки росы в эволюции наземных растений и на разработку новых подходов к селекции засухоустойчивых культур.

Работа выполнена при поддержке Программы стратегического развития Петрозаводского государственного университета.

\section{Литература}

Карпун Ю. Н., Коннов Н. А., Кувайцев М. В., Прохоров А. А. Активная конденсация атмосферной влаги как механизм самоорошения почвопокровных растений [Active condensation of the atmospheric moisture as a self-irrigation mechanism for the ground-covering plants] // Hortus bot. 2015. T. 10. C. 11-17. URL: http://hb.karelia.ru/journal/article.php?id=2802. DOI: 10.15393/j4.art.2015.2802.

Кирлиан В. Х., Кирлиан С. Д. В мире чудесных разрядов. [In a world of wonderful charge] М.: Знание, 1964. 40 c.

Лархер В. Экология растений. [Plant Ecology] М.: Мир, 1978. С. 291.

Прохоров А. А. Активная конденсация воды растениями // Принципы экологии. [Active condensation of water by plants // Priciples of Ecology] ПетрГУ, 2013. № 3. С. 58-61. DOI: 10.15393/j1.art.2013.2921.

Прохоров А. А. Точка росы - неизученный фактор в экологии, физиологии и интродукции растений [Dewpoint - unstudied factor in ecology, physiology and plant introduction] // Hortus bot. 2015a. T. 10. С. 4-10. URL: http://hb.karelia.ru/journal/article.php?id=2801. DOI: 1.10.15393/j4.art.2015.2801.

Прохоров А. А. Оптимальные климатические условия для конденсации атмосферной влаги на поверхности растений [Ideal climatic conditions for condensation of atmospheric moisture on the plants' surface] // Hortus bot. 2015b. T. 10. C. 18-24. URL: http://hb.karelia.ru/journal/article.php?id=3143. DOI: 10.15393/j4.art.2015.3143.

Beysens D. The formation of dew // Atmospheric Research. 1995. T. 39. № 1-3. C. $215-237$. DOI:10.1016/0169-8095(95)00015-J.

Curtis O. F. Leaf temperatures and the cooling of leaves by radiation // Plant Physiol. 1936. T. 11. № 2. P. 343-364.

Gates D. M. Transpiration and Leaf Temperature // Annual Review of Plant Physiol. 1968. T. 19. P. $211-238$.

Gausman H. W., Cardenas R. Effect of Leaf Pubescence of Gynura aurantiaca on Light Reflectance // Botanical Gazette. 1969. T. 130. № 3. DOI: 10.1086/336484.

Lange O. L. и Lange R. Untersuchungen uber Blattemperaturen, Transpiration und Hitzeresistenz an Pflanzen mediterraner Standorte (Costabrava, Spanien) // Flora. 1963. V. 153. S. 387-425. 
Malik F. T., Clement R. M., Gethin D. T., Krawszik W., Parker A. R. Nature's moisture harvesters: A comparative review // Bioinspiration \& Biomimetics . 2014. V. 9. № 3. DOI: 10.1088/1748-3182/9/3/031002.

Malik F. T., Thomas R. A., Clement R. M., Krawszik W. и Parker A. R. Infrared study of dew harvesting cacti spines // Thermology International. February 2015a. V. 25. № 1. P. 7-13.

Malik F. T., Clement R. M., Gethin D. T., Beysens D. A., Cohen R. E., Krawszik W., Parker A. R. Dew harvesting efficiency of four species of cacti // Bioinspiration \& Biomimetics. 2015b. V. 10. № 3. DOI: 10.1088/1748-3190/10/3/036005.

Mpemba E. В. и Osborne D. G. Cool? // Physics Education. 1969. V. 4. № 3. P. $172-175$. DOI:10.1088/0031-9120/4/3/312.

Tillandsia usneoides // Floridata. Floridata. com LLC. 2015. 06.12.2016. URL: http://floridata.com/Plants/Bromeliaceae/Tillandsia\%20usneoides/571.

\title{
Mechanisms available for cooling plants' surfaces
}

\author{
PROKHOROV \\ Alexey \\ Petrozavodsk State University, alpro@onego.ru
}

\section{Keywords:}

hypothesis, dew point, plants' temperature, dew condensation, light reflection, transpiration, Mpemba effect, thermal radiation, bioelectricity

\section{Annotation:}

The essay briefly touches upon the main mechanisms to cool down the plats' surfaces that lead to condensation of atmospheric moisture; methods for experimental verification of these mechanisms are presented therein.

Цитирование: Прохоров А. А. Возможные механизмы охлаждения поверхности растений // Нortus bot. 2016. T. 11, URL: http://hb.karelia.ru/journal/article.php?id=3862. DOI: 10.15393/j4.art.2016.3862 Cited as: Prokhorov A. A. "Mechanisms available for cooling plants' surfaces" // Hortus bot. 11, (2016): DOI: 10.15393/j4.art.2016.3862 